REVISTA ANDALUZA DE ANTROPOLOGÍA

NÚMERO 18: MIRADAS DESDE LA ANTROPOLOGÍA AMBIENTAL.

ABRIL DE 2020

ISSN 2174-6796

[pp. 172-175]

https://dx.doi.org/10.12795/RAA.2020.18.09

\title{
RESEÑA: Pardo-Tomás, José; Zarzoso, Alfons y Sánchez Menchero, Mauricio. 2019. Cuerpos mostrados. Regímenes de exhibición de lo humano. Barcelona y Madrid, siglos XVII- XX. Barcelona: Anthropos.
}

\author{
Yolanda Aixelá \\ Institución Mila y Fontanals de Investigación en Humanidades (CSIC)
}

Los editores de este libro, José Pardo-Tomás, Alfons Zarzoso y Mauricio Sánchez Menchero, se preguntan sobre las similitudes y diferencias que existen en la exhibición de cuerpos humanos entre los siglos XVII y XX, especialmente en Barcelona y Madrid. La formulación es profundamente antropológica pues el recorrido que proponen los tres editores refleja la distinta relación que ha venido generándose en España durante los últimos siglos gracias a la diversidad de estudios de caso escogidos. De hecho, la trayectoria de estos respecto a los gabinetes de curiosidades y colecciones museísticas es muy extensa, especialmente en los dos primeros.

Este volumen es de vocación interdisciplinar, aunque transita entre lo local y lo global al poner de relieve las maneras de pensar la otredad que emergen en un contexto dado en un período concreto, muchas veces conectadas con otras realidades socioculturales próximas. Y es que Pardo-Tomás y Zarzoso son herederos de una disciplina que conecta las transformaciones científicas con la Antropología y la Historia, mientras Sánchez 
Menchero se ha desarrollado desde la Historia de la Comunicación y la Historia Cultural. El resultado es una magnífica aproximación al fenómeno de la exhibición de lo humano, que se imbrica en historias locales y nacionales, magníficamente prologada por dos de sus editores, Pardo-Tomás y Zarzoso (2019: 6) que en su introducción señalan que la comprensión de la "exhibición de restos humanos... a medio camino entre la divulgación científica y el negocio del espectáculo" depende "de los espacios de exhibición, de los contextos de recepción... de la divergencia de los marcos normativos”, entre otros.

La cuidada edición con un útil índice onomástico, una bibliografía unificada que distingue fuentes manuscritas primarias y secundarias, y un interesante material gráfico, permite situar al lector en los diferentes períodos históricos estudiados de la mano de la Historia, la Historia del Arte, la Biología y la Comunicación. Los editores han estructurado acertadamente los contenidos en tres grandes apartados: Gabinetes, Aulas y Exposiciones.

En Gabinetes, se incluyen los textos de Morcelli Ontiveros, Trias Verbeeck, Ulled i Bertran. El primer texto corresponde de la historiadora Morcelli Ontiveros y se titula "La curiosidad y los hombres: lo "humano en el Gabinete Salvador". En su desearrollo, la autora señala cómo la voluntad por coleccionar se convirtió en una práctica habitual entre los siglos XVII y XVIII, tal como se vio reflejado en la creación de los gabinetes de curiosidades, y particularmente en el gabinete Salvador estudiado previamente por Pardo-Tomás (2014). Morcelli Ontiveros (2019: 33-34) concluye que lo humano tuvo un lugar central en la colección, y que ésta estuvo al alcance de diferentes públicos gracias a su formato físico y textual. Por su parte, Trias Verbeeck aborda "La humanización del mar. Seres marinos personificados en el Gabinete Salvador”. En el texto, la autora se aproxima al mar desde los diferentes materiales que directa o indirectamente contiene la colección Salvador. Como resultado, observa los mapas y los elementos relacionados con el mar, atendiendo especial atención a las sirenas, por lo que se plantea si las colecciones son gabinetes de lo real o de lo imaginado. El último trabajo de este bloque es de Ulled i Bertrán que ofrece la tercera aproximación con el capítulo titulado "De gabinete a museo. Pomonas y anatomías en la Barcelona liberal, entre la educación, el comercio y la ciencia". En su texto, ofrece una explicación articulada en diferentes ejes de corte cultural, económico y científico, sobre la transformación que sufrieron algunos gabinetes de curiosidades a primeros del siglo XIX, como los dos estudios de caso que analiza: la Colección Salvador y la Colección José Soler y Cosp. Su trabajo concluye entre otros que la intención educadora de los exhibidores de los materiales les llevó a ser "agentes selectores".

El segundo apartado está dedicado a las Aulas y contiene los textos de Morente, Torres Gallardo y Zarzoso. El primer trabajo corresponde a Morente y se titula "Arte para la anatomía. Materialidad didáctica en el Real Colegio de Cirugía de San Carlos de 
Madrid". En el texto, la autora revisa la plasmación visual del conocimiento científico de esta colección, centrándose también en la consideración artística de las figuras de cera. Morente (2019: 85) señala la doble dimensión de los objetos pues "nos encontramos frente a dos formas de mirar el mundo, de construirlo", por lo que distingue el "hombre" de ciencia y la mirada del artista" (Morente 2019: 85). Por su parte, Torres Gallardo titula su aportación "Anatomía proyectada en el aula. Las placas de vidrio de la Facultad de Medicina de la Universidad de Barcelona (1890-1950)". Torres Gallardo (2019: 97) ofrece un extenso análisis de las placas con representaciones visuales de anatomía humana, que desde finales del siglo XIX y mediados del XX, constituían un recurso de enseñanza de la anatomía en las universidades y concretamente en la de Barcelona. Cierra este apartado Zarzoso con el texto “¿Dónde está la pierna de Ramon Turró? Tras las colecciones del Museo de Patología de la Universidad de Barcelona”. En él, Zarzoso (2019: 117) aborda la singularidad que supuso la donación de la pierna izquierda de Turró, "entendida como pieza museológica... una de las formas sobre cómo se produjo la construcción y desarrollo de la colección". En este sentido, Zarzoso (2019: 137) reflexiona sobre el museo como forjador de ciencia y de espacio científico, al tiempo que aborda cómo "los sujetos -pacientes- se convirtieron en objetos médicos".

El tercer apartado está dedicado a las Exposiciones, con textos de Sharpe, Haydeé Bravo y Sánchez Menchero. Sharpe con el título "Un médico en el cementerio. Arte, muerte y anatomía en la tumba escultórica del Dr. Jaime Farreras Framis (Barcelona, 18871888)" dedica su capítulo al esqueleto de mármol de la tumba. Para Sharpe (2019: 141) esta constituye "un punto de encuentro entre dos espacios -el cementerio y el museo anatómico-, dos profesiones -escultor y médico-, y dos formas de acercarse y entender el cuerpo humano". El segundo texto es de Haydeé Bravo y se titula "La exhibición del cuerpo nacional. Maniquíes, cráneos y tipos indígenas mexicanos en Madrid, 1892". Haydeé Bravo (2019: 162) puntualiza que en la exhibición de humanos que tuvo lugar en diferentes ciudades españolas de finales del XIX y primeros del XX estudiados, entre otros por Sánchez Gómez (2006), hubo casos en que diferentes países no enviaron "pareja alguna de indígenas vivos" para ser expuestos. Por ello, en su caso, estudia los maniquíes de guerreros aztecas, las fotografías de "tipos indígenas" y cráneos y restos humanos, desde una perspectiva próxima a la etnología que denuncia la necropolítica del saber incorporada en el discurso nacional. Por último, Sánchez Menchero titula su texto "Otredades desproporcionadas, materialidad fotográfica y régimen de exhibición (siglos XIX-XX)”. En el texto, Sánchez Menchero (2019: 183) se adentra en la curiosidad por "los seres humanos de talla baja" como "objetos mostrados" desde la colección Ardavín-Parish de la Biblioteca Nacional de España. El autor estudia la fotografía como reflejo del contexto, con agentes, instituciones, tecnología y mecanismos de producción y distribución, consciente de la escasa información que se tiene de estos artistas, sus ropas y escenografías, y de la variedad existente de estilos fotográficos. 
El libro se cierra con el epílogo de Pardo-Tomás y Zarzoso "Cultura material y regímenes de exhibición. Una propuesta para continuar". En el texto, Pardo-Tomás y Zarzoso (2019:201) se proponen recapitular para "entender históricamente la exhibición del cuerpo humano o las representaciones de lo humano", pues se trata de recomponer las diversidades de los estudios de caso para obtener conclusiones generales sobre la temática. Y concluyen que "gabinetes, aulas y exposiciones son espacios para la acumulación de lo humano y de su representación” (2019: 206).

Por todo lo mencionado, debe señalarse que este libro constituye una aportación coral, equilibrada y ambiciosa a la exhibición de cuerpos humanos. Sólo se ha echado a faltar algún texto que hubiera reflexionado sobre la centralidad masculina que caracterizó el discurso dominante en las colecciones de lo humano, pues no hay duda que el cuerpo femenino y las mujeres también estuvieron presentes en las colecciones y en los estudios sobre lo humano, aunque en menor medida. En cualquier caso, el volumen es altamente recomendable para antropólogos e historiadores que se adentren en las bases de la concepción y construcción de lo humano y sus diversidades en la España del siglo XVII al XX.

\section{BIBLIOGRAFÍA}

Pardo-Tomás, José. 2014. Salvadoriana. El gabinet de curiositats de Barcelona / El gabinete de curiosidades de Barcelona / The Cabinet of Curiosities of Barcelona. Barcelona: Ajuntament de Barcelona.

Sánchez Gómez, Luís Ángel. 2006. "África en Sevilla: la exhibición colonial de la Exposición Iberoamericana de 1929”. Hispania LXVI/224: 1045-1082. 